\title{
Risk Evaluation of Fresh Products Supply Chain under New Retail Mode
}

\author{
Hua Gao ${ }^{a}$, Xiaopeng Wang ${ }^{b}$ \\ School of Management, Tianjin University of Technology, Tianjin 300384, China. \\ alotusgh@126.com, bwangxiaopeng_0@163.com
}

\begin{abstract}
The risk of Fresh Products Supply Chain includes supplier risk, retailer risk, customer demand risk and the e-commerce platform risk from the perspective of supply chain depot under new retail mode. Based on the analysis of these risk factors, we established a risk evaluation index system, built an unascertained measure model, and evaluated the risks. The research showed that the structure of risks had changed and the emphasis of risks had moved. Under the new retail mode, the supplier's risk and the e-commerce platform risk belong to a higher level. Meanwhile, retailer risk and customer demand risk belong to a middle level. So, we should particularly enhance the management and controlling of the supplier's risk and the e-commerce platform risk.
\end{abstract}

Keywords: new retail mode; fresh products supply chain; risk evaluation; unascertained measure model.

\section{Introduction}

New retail is a deep integration of online, offline and modern logistics under the driven data. From Hema to Meituan Palm Fish Fresh Food, offline physical retail and online e-commerce enterprises are exploring new retail models. New retail can use new technology to explore potential customers, and it also through real-time logistics to improve logistics services. However, the new retail model also brings new risks to the supply chain, especially the risks arising from the operation of ecommerce platform. If these risks cannot be well controlled and evaded, it may become an obstacle to the development of fresh supply chain. Moreover, fresh products is a kind of fast-moving consumer goods which is not easy to preserve, perishable and seasonal, and requires higher risk management ability of supply chain[1]. Therefore, the risk analysis and evaluation of fresh supply chain under new retail mode is helpful to the risk management and control of fresh supply chain under new retail mode.

Many scholars have studied the influencing factors of supply chain risk. According to the three levels of the Internet of Things, Bo Y et al. thought that the risk factors of agricultural products supply chain are divided into perception level risk, network level risk, application level risk and other risks[2]. Hao $\mathrm{Z}$ and Mingkun $\mathrm{W}$ took customer satisfaction as a measure of supply chain failure risk, and take product quality, product price and service level as direct factors, and at last they determine 24 indirect factors[3]. Juan X and Debing B thought the sudden risk of fresh agricultural products supply chain can be divided into production risk, operation risk and demand mutation risk[4]. Qingxing Dong and Orrin Cooper constructed a risk assessment framework by risk identification, risk assessment, risk factors ranking and risk results analysis, and identified 31 risk factors[5]. Sreedevi R. and Haritha Saranga used supply chain flexibility as moderator to study the impact of environmental uncertainty on supply chain risk[6].

The above literature is mainly for the analysis and evaluation of the overall risk of the supply chain. On the contrary, in order to make the core enterprises of the supply chain better understand and manage the risk of the supply chain under the new retail mode, this study re-divides the risk of the supply chain from the point of view of the node enterprises of the supply chain, which analyzes and evaluates the risk of the fresh supply chain under the new retail mode.

\section{The Risk Assessment of Fresh Supply Chain under New Retail Mode}

According to the existing literature and the opinions of relevant experts, we can divide the risk of fresh supply chain under the new retail mode into four first-level indicators and 13 second-level indicators. The unascertained measurement method was initially applied to the comprehensive 
evaluation of environmental quality in the field of mining engineering. In recent years, it has gradually penetrated into the study of risk assessment. The unascertained measurement method can effectively combine all kinds of uncertain information in the evaluation, which reduces the impact of man-made uncertainties on the evaluation results in risk assessment, and makes the evaluation results more accurate. Therefore, this study adopted the unascertained measure to evaluate the risks in the new retail mode. The specific assessment steps were as follows:

\subsection{The Determination of Evaluation Grade}

According to the principle of order, we divided the rating into 4 grades (Highest risk V1, higher risk V2, medium risk V3 and low risk V4), which is used as a basis for questionnaires. The score belongs to the percentage system as shown in Table 1 .

Table 1. The risk assessment scale of fresh supply chain under the new retail mode

\begin{tabular}{ccccc}
\hline Risk grade & Highest risk A & higher risk B & medium risk C & low risk D \\
\hline Risk score & $90-100$ & $80-90$ & $70-80$ & Below 70 \\
\hline
\end{tabular}

Based on the above rating scale, we can construct evaluation space $B=\left(b_{1}, b_{2}, b_{3}, b_{4}\right) . b_{1}, b_{2}, b_{3}, b_{4}$ is four grades, $\mathrm{A}, \mathrm{B}, \mathrm{C}$ and $\mathrm{D}$ respectively $(\mathrm{A}>\mathrm{B}>\mathrm{C}>\mathrm{D})$. So $b_{1}, b_{2}, b_{3}, b_{4}$ satisfies $b_{1}>b_{2}>b_{3}>b_{4}$. In other words, $B=\left(b_{1}, b_{2}, b_{3}, b_{4}\right)$ is an ordered set. We set evaluation indicators as $A=\left(a_{1}, a_{2}, \cdots, a_{n}\right)$. The evaluation index $a_{i}(1 \leq i \leq n)$ has $m$ influence factors $\left(a_{i 1}, a_{i 2}, \ldots, a_{i m}\right) . x_{i j}$ indicates observation value of the evaluation index $a_{i}$ under the influence factor $a_{i j}(1 \leq j \leq m)$.

In order to determine the risk score of fresh supply chain under the new retail mode, we conducted a questionnaire survey to relevant experts and managers engaged in fresh supply chain. A total of 50 questionnaires were distributed and 44 valid questionnaires were collected, which is an effective recovery rate of $88 \%$. Then we averaged the risk score and got the average score of each risk factor. The result is shown in Table 2 .

Table 2. The risk factors of fresh supply chain in new retail mode

\begin{tabular}{|c|c|c|c|c|c|c|c|}
\hline \multirow{2}{*}{$\begin{array}{l}\text { Risk } \\
\text { types }\end{array}$} & \multicolumn{3}{|c|}{ Supplier risk A1 } & \multicolumn{4}{|c|}{ Retailer risk A2 } \\
\hline & A11 & $\mathrm{A} 12$ & $\mathrm{~A} 13$ & $\mathrm{~A} 21$ & $\mathrm{~A} 22$ & A23 & $\mathrm{A} 24$ \\
\hline $\begin{array}{l}\text { Risk } \\
\text { factor }\end{array}$ & $\begin{array}{l}\text { Delivery } \\
\text { timeliness }\end{array}$ & $\begin{array}{c}\text { cargo } \\
\text { damage and } \\
\text { shortage }\end{array}$ & $\begin{array}{l}\text { Product } \\
\text { quality }\end{array}$ & $\begin{array}{l}\text { Logistics } \\
\text { delay }\end{array}$ & $\begin{array}{l}\text { Demand } \\
\text { forecast } \\
\text { bias }\end{array}$ & $\begin{array}{l}\text { Distribution } \\
\text { risk }\end{array}$ & $\begin{array}{l}\text { Operational } \\
\text { risk }\end{array}$ \\
\hline $\begin{array}{l}\text { Index } \\
\text { score }\end{array}$ & 85 & 84 & 87 & 83 & 82 & 77 & 82 \\
\hline \multirow{2}{*}{$\begin{array}{l}\text { Risk } \\
\text { types }\end{array}$} & \multicolumn{3}{|c|}{ Customer demand risk A3 } & \multicolumn{4}{|c|}{ E-commerce platform risk A4 } \\
\hline & A31 & A32 & A33 & A41 & $\mathrm{A} 42$ & A43 & \\
\hline $\begin{array}{l}\text { Risk } \\
\text { factor }\end{array}$ & $\begin{array}{l}\text { Seasonal } \\
\text { change }\end{array}$ & $\begin{array}{l}\text { Customer } \\
\text { preferences } \\
\text { change }\end{array}$ & $\begin{array}{l}\text { Direction } \\
\text { of public } \\
\text { opinion }\end{array}$ & $\begin{array}{l}\text { Information } \\
\text { technology }\end{array}$ & $\begin{array}{l}\text { Information } \\
\text { security }\end{array}$ & $\begin{array}{l}\text { Network } \\
\text { instability }\end{array}$ & \\
\hline $\begin{array}{l}\text { Index } \\
\text { score }\end{array}$ & 75 & 76 & 75 & 78 & 87 & 89 & \\
\hline
\end{tabular}

\subsection{The Construction of Membership Function}

According to the risk rating table, we constructed membership functions $u\left(a_{i j} \subseteq b_{k}\right)$ by classification criteria.

$$
u\left(a_{i j} \in b_{1}\right)=\left\{\begin{array}{cc}
0 & x<80 \\
\frac{x-80}{85-80} & 80 \leq x<85 \\
1 & x \geq 85
\end{array} ; u\left(a_{i j} \in b_{2}\right)=\left\{\begin{array}{cc}
\frac{x-70}{80-70} & 70 \leq x<80 \\
\frac{85-x}{85-80} & 80 \leq x<85 \\
0 & x<75 \cup x \geq 85
\end{array}\right.\right.
$$




$$
u\left(a_{i j} \in b_{3}\right)=\left\{\begin{array}{cc}
\frac{x-65}{70-65} & 65 \leq x<70 \\
\frac{80-x}{80-70} & 70 \leq x<80 \\
0 & x<75 \cup x \geq 85
\end{array} ; u\left(a_{i j} \in b_{4}\right)=\left\{\begin{array}{cc}
1 & x<65 \\
\frac{70-x}{70-65} & 65 \leq x<70 \\
0 & x \geq 70
\end{array}\right.\right.
$$

We substituted each observation value $x_{i j}$ into membership function $u\left(a_{i j} \subseteq b_{k}\right) . \quad u_{i j k}=u\left(a_{i j} \subseteq b_{k}\right)$ indicating that $a_{i j}$ is the degree of evaluation level $b_{k}$ is called the measurement of $a_{i j} .\left(u_{i j k}\right)_{m \times k}$ is a single index measure matrix of $a_{i}$. For example, we brought A11, A12, A13 to the membership function, we can get $u_{111}=0 \quad u_{112}=1 \quad u_{113}=0 \quad u_{114}=0, \quad u_{121}=0 \quad u_{122}=0.9 \quad u_{123}=0.1 \quad u_{124}=0$ and $u_{131}=0.4 \quad u_{132}=0.6 \quad u_{133}=0 \quad u_{134}=0$.

Thus, an unascertained measure matrix $\left(u_{1 i j}\right)_{3 \times 4}$ of supplier risk index A1 was constructed. In like manner,

$$
\begin{aligned}
& \left(u_{1 i j}\right)_{3 \times 4}=\left[\begin{array}{cccc}
0 & 1 & 0 & 0 \\
0 & 0.9 & 0.1 & 0 \\
0.4 & 0.6 & 0 & 0
\end{array}\right] ; \quad\left(u_{2 i j}\right)_{4 \times 4}=\left[\begin{array}{cccc}
0 & 0.8 & 0.2 & 0 \\
0 & 0.7 & 0.3 & 0 \\
0 & 0.2 & 0.8 & 0 \\
0 & 0.7 & 0.3 & 0
\end{array}\right] \\
& \left(u_{3 i j}\right)_{3 \times 4}=\left[\begin{array}{cccc}
0 & 0 & 1 & 0 \\
0 & 0.1 & 0.9 & 0 \\
0 & 0 & 1 & 0
\end{array}\right] ; \quad\left(u_{4 i j}\right)_{3 \times 4}=\left[\begin{array}{cccc}
0 & 0.3 & 0.7 & 0 \\
0.4 & 0.6 & 0 & 0 \\
0.8 & 0.2 & 0 & 0
\end{array}\right] .
\end{aligned}
$$

\subsection{Calculate Classification Weight}

We use information entropy to calculate the classification weight of indexes.

$$
\begin{gathered}
P(j)=-\sum_{k=1}^{K} u_{i j k} \cdot \log u_{i j k} \\
v_{\mathrm{ij}}=\frac{1-\frac{1}{\log K} P(j)}{\sum_{j=1}^{m} 1-\frac{1}{\log K} P(j)}
\end{gathered}
$$

$P(j)$ : The Information entropy of $u_{i j k} v_{\mathrm{ij}}$ : the classification weight of $a_{i j}\left(0 \leq v_{\mathrm{ij}} \leq 1\right.$ and $\left.\sum_{j=1}^{m} v_{i j}=1\right)$.

The value of A1 is brought in Formula 1 and Formula 2, and we can get $v_{1 \mathrm{j}}=(0.42,0.34,0.24)$. In like manner, we can get $v_{2 \mathrm{j}}=(0.26,0.24,0.26,0.24), v_{3 \mathrm{j}}=(0.36,0.28,0.36)$ and $v_{4 \mathrm{j}}=(0.33,0.31,0.36)$.

\subsection{Comprehensive Measure}

We can get the comprehensive evaluation matrix $a_{i}$ of evaluation index $\left(u_{i j}\right)_{\mathrm{n} \times k}$ from single index measure matrix $\left(u_{i j k}\right)_{m \times k}$ to classification weight of each index $v_{\mathrm{ij}}$.

$$
\left(u_{i 1}, u_{i 2}, \ldots, u_{i K}\right)=\left(v_{i 1}, v_{i 2}, \ldots, v_{i K}\right) \cdot\left(u_{i j k}\right)_{m \times k}
$$

According to formula 3, we can draw comprehensive measures of A1, A2, A3 and A4. As follows:

$$
u_{1}=v_{1 j} \cdot\left(u_{1 j k}\right)_{3 \times 4}=(0.096,0.87,0.034,0), u_{2}=v_{2 j} \cdot\left(u_{2 j k}\right)_{4 \times 4}=(0,0.596,0.404,0) \text {, }
$$




$$
u_{3}=v_{3 j} \cdot\left(u_{3 j k}\right)_{3 \times 4}=(0,0.028,0.972,0), u_{4}=v_{4 j} \cdot\left(u_{4 j k}\right)_{3 \times 4}=(0.412,0.357,0.231,0) .
$$

\subsection{The Confidence Level Recognition}

Because the classification of evaluation grade is orderly, the maximum membership recognition criterion is not applicable, so the confidence recognition criterion is introduced. $\lambda$ is introduced as confidence level. If there is an order in the evaluation space $\left(u_{1}>u_{2}>\cdots>u_{K}\right)$ and $k_{0}=\min \sum_{i=1}^{k} u_{k}>\lambda(k=1,2, \cdots, K)$, the evaluation object belongs to the level $C_{k_{0}}$. We got $\lambda=0.7$. we got the preliminary results. Supplier risk assessment level is B level. The retailer's risk rating is C level. Customer demand risk rating is $\mathrm{C}$ level. The risk rating of e-commerce platform is $\mathrm{B}$ level.

\section{Conclusion}

In the fresh supply chain under the new retail mode, the focus of risk management in the fresh supply chain has changed. Supplier risk and e-commerce platform risk belong to higher level risk, while retailer risk and customer demand risk belong to medium risk. Our findings are slightly different from those of Manikandan L, which show that traditional supply chain risk managers should focus on demand risk and supply risk[7]. The reason is that the fresh supply chain under the new retail mode is based on the Internet, integrating online and offline to integrate supply chain. However the potential uncertainty of the Internet will create the risk of e-commerce platform for the fresh supply chain under the new retail mode. In order to cope with the change of the risk structure of fresh supply chain under the new retail mode, it is necessary to evaluate the supplier's risk regularly and control the risk magnitude. Managers should strengthen the risk management of E-commerce platform, improve the risk management ability of retailers, and use network technology to forecast customer demand more accurately. Only by using these methods can we reduce the risk of customer demand in the fresh supply chain. On the whole, in order to manage the risks in the fresh supply chain under the new retail mode, every node enterprise in the supply chain should focus on the risk management of supplier risk and e-commerce platform risk.

\section{Acknowledgments}

This paper was funded by The National Natural Science Foundation of China (NO.71471131), and supported by Tianjin University Innovation Team Construction Project(N0.TD13-5018).

\section{References}

[1]. Yingyu Z, Mengjia Z, Qiang W et al. Research on purchase intention of fresh agricultural products under $\mathrm{O} 2 \mathrm{O}$ mode based on perceived benefit and perceived risk framework[J]. China Soft Science, (2015) No. 06, p. 129.

[2]. Bo Y, Ping S, Delong D. Risk assessment and control of agricultural product supply chain under the environment of Internet of things[J]. Journal of Engineering Management, Vol. 28 (2014) No. 3, p. 196-202.

[3]. Hao Z, Mingkun W. Risk identification model and Simulation of supply chain failure under O2O mode[J]. Journal of System Simulation, Vol. 28 (2016) No. 11, p. 2747-2755.

[4]. Juan X, Debing Z. Risk assessment model for fresh agricultural product supply chain[J]. Statistics \& Decision, (2012) No. 12, p. 41-43.

[5]. Dong Q, Cooper O. An orders-of-magnitude AHP supply chain risk assessment framework[J]. International Journal of Production Economics, Vol. 182(2016) , p. 144-156. 
[6]. Sreedevi R, Saranga H. Uncertainty and supply chain risk: The moderating role of supply chain flexibility in risk mitigation[J]. International Journal of Production Economics, Vol. 193 (2017), p. 332-342.

[7]. Manikandan L, Thamaraiselvan N, Punniyamoorthy M. Assessment of supply chain risk: scale development and validation[J]. Benchmarking An International Journal, Vol. 20 (2013) No. 1, p. 84-85. 